\title{
Requests for somatic support after neurologic death determination: Canadian physician experiences
}

\section{Demandes de soutien des fonctions vitales après un diagnostic de décès neurologique : les expériences des médecins canadiens}

\author{
Amanda van Beinum, MSc $\mathbb{1} \cdot$ Andrew Healey, MD • Jennifer Chandler, LLM • \\ Sonny Dhanani, MD • Michael Hartwick, MD, MEd • \\ Ariane Lewis, MD • Calista Marshall, BSc • Jocasta Marshall, LLB • \\ Sam Shemie, MD • Jeffrey M. Singh, MD, MSc
}

Received: 5 July 2020/Revised: 24 August 2020/ Accepted: 28 August 2020/Published online: 10 November 2020

(C) Canadian Anesthesiologists' Society 2020, corrected publication 2020

\begin{abstract}
Purpose Neurologic determination of death (NDD) is legally accepted as death in Canada but remains susceptible to misunderstandings. In some cases, families request continued organ support after NDD. Conflicts can escalate to formal legal challenges, causing emotional, financial, and moral distress for all involved. We describe prevalence, characteristics, and common experiences with requests for continued organ support following NDD in Canada.
\end{abstract}

Electronic supplementary material The online version of this article (https://doi.org/10.1007/s12630-020-01852-9) contains supplementary material, which is available to authorized users.

A. van Beinum, MSc ( $\square)$

Department of Sociology and Anthropology, Carleton

University, B750 Loeb Building, 1125 Colonel By Drive,

Ottawa, ON K1S 5B6, Canada

e-mail: amanda.vanbeinum@carleton.ca

A. Healey, MD

Critical Care, William Osler Health System, Brampton, ON, Canada

Division of Emergency Medicine, McMaster University,

Hamilton, ON, Canada

J. Chandler, LLM

Centre for Health Law, Policy and Ethics, Faculty of Law,

University of Ottawa, Ottawa, ON, Canada

S. Dhanani, MD

Department of Critical Care, Children's Hospital of Eastern

Ontario, Ottawa, ON, Canada

Faculty of Medicine, University of Ottawa, Ottawa, ON, Canada
Methods Mixed-methods design combining anonymous online survey with semi-structured interviews of Canadian critical care physicians (448 practitioners, adult and pediatric).

Results One hundred and six physicians responded to the survey and 12 participated in an interview. Fifty-two percent (55/106) of respondents had encountered a request for continued organ support after NDD within two years, $47 \%$ (26/55) of which involved threat of legal action. Requests for continued support following NDD ranged from appeals for time for family to gather before ventilator removal to disagreement with the concept of NDD. Common responses to requests included: consultation with an additional physician (54\%), consultation with

M. Hartwick, MD, MEd

Department of Medicine, University of Ottawa, Ottawa, ON, Canada

Divisions of Critical Care and Palliative Medicine, The Ottawa Hospital, Ottawa, ON, Canada

A. Lewis, MD

Departments of Neurology and Neurosurgery, Affiliate of the Department of Population Health-Division of Medical Ethics, NYU Langone Medical Center, New York, NY, USA

C. Marshall, BSc

Royal College of Surgeons, Dublin, Ireland

J. Marshall, LLB

St. George's University School of Medicine, St. George's, Grenada 
spiritual services (41\%), and delay of one to three days for NDD acceptance (49\%). Respondents with prior experience were less likely to recommend ancillary tests $(P=0.004)$ or consultation with bioethics services $(P=$ 0.004). Qualitative analysis revealed perceptions that requests for continued organ support were driven by mistrust, tensions surrounding decision-making, and cultural differences rather than a lack of specific information about NDD.

Conclusions Family requests for continued somatic support following NDD were encountered by half our sample of Canadian critical care physicians. Mitigation strategies require attention to the multifaceted social contexts surrounding these complex scenarios.

\section{Résumé}

Objectif Au Canada, le diagnostic de décès neurologique (DDN) est légalement accepté en tant que décès, mais il est encore mal compris parfois. Dans certains cas, les familles demandent de maintenir artificiellement les fonctions vitales après un DDN. Les conflits peuvent dégénérer et devenir des contestations judiciaires formelles, provoquant de la détresse émotionnelle, financière et morale pour tous. Nous décrivons la prévalence, les caractéristiques et les expériences fréquemment vécues en lien avec des demandes de maintien artificiel des fonctions vitales après un DDN au Canada.

Méthode Méthodologie mixte combinant un sondage électronique anonyme à des entretiens semi-structurés de médecins intensivistes canadiens (448 praticiens, populations adulte et pédiatrique).

Résultats Cent six médecins ont répondu au sondage et 12 ont participé à un entretien. Cinquante-deux pour cent (55) 106) des répondants avaient déjà reçu une demande de maintien des fonctions vitales après un DDN au cours des deux dernières années, dont $47 \%$ (26/55) étaient accompagnées de menaces de poursuite judiciaire. Les demandes de maintien continu à la suite d'un DDN allaient des requêtes de temps supplémentaire pour que la famille puisse se réunir avant de débrancher le respirateur aux désaccords quant au concept même de DDN. Les réponses fréquentes aux demandes étaient : la consultation d'un autre médecin (54\%), la consultation des services spirituels (41\%), et un délai d'un à trois jours pour

\footnotetext{
S. Shemie, MD

Division of Pediatric Critical Care, Montreal Children's Hospital, McGill University Health Centre, Montreal, QC, Canada

J. M. Singh, MD, MSc

Interdepartmental Division of Critical Care Medicine, University of Toronto, Toronto, ON, Canada
}

accepter le DDN (49\%). Les répondants ayant déjà eu une expérience similaire avaient moins tendance à recommander des tests supplémentaires $(P=0,004)$ ou une consultation auprès des services de bioéthique $(P=$ 0,004). L'analyse qualitative a révélé des perceptions selon lesquelles les demandes de maintien des soins étaient motivées par la méfiance, des tensions autour de la prise de décision et des différences d'ordre culturel plutôt que par le manque d'informations spécifiques concernant le DDN. Conclusion La moitié de notre échantillon de médecins intensivistes canadiens ont déjà été confrontés à des demandes de la famille pour maintenir le soutien des fonctions vitales à la suite d'un DDN. Les stratégies de mitigation doivent tenir compte des contextes sociaux aux multiples facettes entourant ces situations complexes.

Keywords neurologic determination of death .

brain death · organ support · family - physician experience

\section{Introduction}

Neurologic determination of death (NDD) is legally accepted as death in Canada and around the world. ${ }^{1}$ Once death has been declared using neurologic criteria, routine practice is to discontinue organ support (e.g., mechanical ventilation and vasopressors) unless deceased organ donation is planned. While NDD has been part of clinical practice for 50 years, $^{2}$ it remains subject to misunderstandings ${ }^{3-9}$ due to philosophical and religious disagreements about what constitutes human death, ${ }^{10,11}$ complexities in the clinical practice of death determination, ${ }^{12,13}$ inconsistencies in terminology and language used to describe $\mathrm{NDD}^{10}$ and cognitive dissonance involved in declaring as dead a person that continues to have some degree of biologic function. ${ }^{14-17}$ Finally, despite legal precedent supporting acceptance of neurologic criteria for determining death, NDD remains legally undefined in most provinces.

In some cases, differences in understanding can lead to situations in which families request prolonged organ support or object to discontinuation of organ support after NDD. Families may cite religious objections to the concept of NDD and the desire to continue supporting loved ones whom they regard as alive. In contrast, physicians may feel an ethical and societal obligation not to prolong the inevitable decline of the body of a deceased person. ${ }^{18,19}$ These complex scenarios can lead to legal conflict between the patient's family and the medical team, a situation which occurred in the publicized cases of Taquisha McKitty $^{20,21}$ and Shalom Ouanounou ${ }^{22}$ in Canada, and Jahi McMath ${ }^{19,23-25}$ in the United States. In these cases, legal conflict centred around whether and when 
organ support could be stopped for a patient determined dead using medically accepted criteria, and whether or not religious objections to the concept of NDD should prohibit removal of organ support. In prolonged disputes, both families and physicians face the risk of moral distress and its psychological consequences. ${ }^{26,27}$ Understanding which situations are likely to lead to conflict as well as how disagreements might be defused prior to legal involvement could help to prevent distress.

Recent surveys of physicians in the United States indicate $47 \%$ of adult and $61 \%$ of pediatric neurology practitioners have encountered requests for continued organ support following NDD. ${ }^{28,29}$ The prevalence of this phenomenon has not been explored in Canada, though evidence suggests requests for continued support may occur in up to $10 \%$ of NDD cases. ${ }^{30}$ Four American states currently offer accommodations for religious or moral objections to the use of neurologic criteria to determine death. ${ }^{29}$ Similar legislative accommodations are not presently offered in Canadian jurisdictions. ${ }^{21}$ Additionally, differences in healthcare funding models between the United States and Canada generate unique considerations about who should pay for extended organ support after NDD and may limit generalizability of findings to Canadian contexts. An understanding of whether and how Canadian physicians experience requests for continued organ support following NDD may help determine whether further guidance on this issue is required.

In this study, we sought to describe the prevalence and characteristics of requests for continued organ support following NDD, along with common strategies for dispute resolution as practiced in Canada.

\section{Methods}

We used a mixed-method design combining a survey with semi-structured interviews of Canadian critical care physicians. All participants read and acknowledged a letter of information and consent prior to completing the online, anonymous survey. The consent letter was reviewed with all interview participants. This study was approved by the Research Ethics Board of the William Osler Health System (REB File No. 18-0072). Since this project focused on the experiences of physicians, we did not engage with patients, allied healthcare workers, or the public when designing this study. Our study team included two experienced qualitative researchers (A.V.B., J.C.) as well as physicians with personal experience of a family request for continued organ support after NDD (A.H., A.L., J.M.S., S.D.).

\section{Electronic survey}

We created an anonymous, self-administered, electronic survey for Canadian critical care physicians in accordance with existing survey development guidelines. ${ }^{31}$ An initial list of potential survey domains (Appendix A) was narrowed down through an iterative process of review and testing with a small group of leaders in Canadian critical care practice, including four adult and two pediatric intensivists. To minimize survey completion time, the survey was reduced to 15-20 closed-ended questions (Appendix B). To test for construct and face validity draft surveys were pilot tested on seven critical care physicians with varying experience with NDD. Survey development and testing took place between August and November 2018.

A final version of the survey was uploaded to a secure online hosting platform (SurveyMonkey) and sent via email link in December 2018 to the Canadian Critical Care Society mailing list of critical care physicians in Canada ( $n$ $=448$ ). An introductory email encouraging survey completion was sent in advance. The survey was also advertised during a plenary on NDD at the Canadian Critical Care Forum in Toronto in November 2018. A reminder email was sent after one week, two weeks, and one month. A question at the beginning of the survey excluded potential participants who did not practice critical care in Canada (e.g., health professionals and researchers who may have heard about the survey at the conference).

Survey data were analyzed using STATA/SE version 16 (StataCorp in College Station, TX, USA). Significance testing of categorical variables was performed using twosided Fisher's exact tests. Open-ended survey responses were included with interview transcripts for thematic coding.

\section{In-depth interviews}

To obtain a comprehensive understanding of physicians' experiences with requests for continued organ support following NDD, we asked survey respondents to participate in an interview. Respondents who agreed were directed to a separate survey where they provided contact details for interview scheduling. The interview guide for the semi-structured interviews (see Appendix C) was built from questions in the online survey, but was designed to seek additional detail. Interview questions were openended, allowing participants to focus on aspects of requests for continued organ support after NDD most important to them, following accepted practice for qualitative methodologies. ${ }^{32}$

All interviews were conducted by phone or in person and digitally audio-recorded by A.V.B, and transcribed by 
A.V.B and C.M. Atlas.ti (Scientific Software Development $\mathrm{GmbH}$, Berlin, Germany) was used for coding and thematic analysis. A qualitative method of constant comparative coding was used to identify recurrent themes. ${ }^{33,34}$ Thematic analysis findings were used to provide context and depth to results obtained from the anonymous electronic survey through a process of triangulation. ${ }^{35,36}$ All ten manuscript authors were involved in the final analysis of qualitative and quantitative data.

\section{Results}

The online survey was completed by $114 / 448$ respondents (25\% response rate). Five respondents indicated they did not practice critical care in Canada, and thus were ineligible for participation; and three respondents declined to participate after reading the initial study information page. The final quantitative analysis sample consisted of 106 surveys. A total of 17/106 survey respondents $(16 \%)$ indicated they would be willing to participate in an interview; 12 physicians $(71 \%$ of those initially interested) completed interviews with the study team (11 by phone, one in person).

\section{Demographics}

Survey respondent demographics are presented in Table 1. Respondents were predominantly male (75/106, 72\%), between the ages of 35 and $44 \mathrm{yr}(41 \%)$, had at least five years of critical care experience $(96 \%)$, and worked with adult patients (86\%) in academic teaching hospitals $(81 \%)$. Overall, 60\% of respondents were from Ontario (49\%) and Quebec (11\%), with 32\% from Western Canada and the remaining $8 \%$ from Atlantic provinces. A third of survey respondents $(31 / 106,29 \%)$ held a formal role as a donation physician. ${ }^{37}$

In-depth interview participants included physicians from across Canada, both adult $(9 / 12,75 \%)$ and pediatric $(3 / 12$, $25 \%)$ practitioners. Half $(6 / 12,50 \%)$ of interview participants held formal roles with organ donation organizations.

Requests for continued organ support and resulting legal actions

The majority $(67 / 106,63 \%)$ of survey respondents indicated they had declared death using neurologic criteria more than 20 times in their career (Table 2). Half of survey respondents $(55 / 106,52 \%)$ had personally interacted with a family request for continued support following NDD within the past two years of their clinical practice (Table 2); of these, 42/55 (76\%) had encountered this type of request only once or twice within the past two years. We found no across-province differences in the reporting of family requests for continued organ support after NDD (Table 3). Of 49 respondents who answered a question about legal aspects of a request for continued organ support after NDD, 26 (53\%) indicated at least one request had involved a threat of legal action (Table 4). Threats progressed to dispute resolution or tribunal in $24 \%$ $(12 / 50)$ of reported cases, and to legal action in $18 \%(9 / 50)$ of reported cases (Table 4).

Of 12 in-depth interview participants, ten (83\%) indicated they had personal experience with families who requested continued organ support following NDD. Interview participants described conflict as uncommon, but noted that addressing conflict caused substantial distress (Electronic Supplementary Material [ESM] eTable 1). Two participants described requests for organ support following NDD as very common ("as high as 50\% of situations"). When asked for clarification, these participants indicated that these requests were usually to provide family members with additional time to be present when the ventilator was removed, and not because they disagreed with determination of death.

No interview participants had been formally involved in a court case surrounding requests for continued organ support following NDD, but one reported going to the Ontario Consent and Capacity Board, and one faced legal proceedings initiated by a family which were abandoned once the patient's heart stopped spontaneously. Two participants described that part of their resolution process involved suggesting families obtain a legal injunction to prevent discontinuation of organ support. Other participants noted families took their own initiative to seek legal counsel (ESM eTable 2).

Perceived causes of requests for continued organ support

When prompted to choose reasons why they perceived families might refuse to discontinue organ support after NDD, 55\% (56/101) of respondents felt it was due to inability to accept death rather than specific difficulty with validity of NDD testing (Table 5). There were no differences in perceived causes of requests for continued support between those with and without personal experience with this issue.

Thematic analysis of interviews with physicians about experiences with specific cases revealed perceptions that a loss of trust in the medical system, the influence of misinformation, and hope for miracles contributed most often to family requests for continued organ support after NDD (ESM eTable 3). Several interview participants also reflected that refusal to discontinue organ support 
Table 1 Demographics of survey respondents ( $n=106$ unless otherwise indicated)

\begin{tabular}{|c|c|c|}
\hline \multicolumn{2}{|l|}{ Demographic variable } & \multirow{2}{*}{$\frac{\text { No. }(\%)}{13(12)}$} \\
\hline Age & $25-34$ & \\
\hline & $35-44$ & $43(40)$ \\
\hline & $45-54$ & $22(21)$ \\
\hline & $55-64$ & $23(22)$ \\
\hline & $65+$ & $4(4)$ \\
\hline & Prefer not to say & $1(1)$ \\
\hline \multirow[t]{3}{*}{ Sex } & Female & $29(27)$ \\
\hline & Male & $75(71)$ \\
\hline & Prefer not to say & $2(2)$ \\
\hline \multirow[t]{8}{*}{ Province } & Alberta & $17(16)$ \\
\hline & British Columbia & $9(8)$ \\
\hline & Manitoba & $5(5)$ \\
\hline & Newfoundland and Labrador & $1(1)$ \\
\hline & Nova Scotia & $7(7)$ \\
\hline & Ontario & $52(49)$ \\
\hline & Québec & $12(11)$ \\
\hline & Saskatchewan & $3(3)$ \\
\hline \multirow[t]{6}{*}{ Years of ICU experience $(n=105)$} & $<1$ & $4(4)$ \\
\hline & $1-5$ & $28(27)$ \\
\hline & $6-10$ & $21(20)$ \\
\hline & $11-15$ & $14(13)$ \\
\hline & $16-20$ & $9(8)$ \\
\hline & $>20$ & $29(28)$ \\
\hline \multirow[t]{8}{*}{ Base specialty $(n=98)^{*}$} & Anesthesia & $17(17)$ \\
\hline & Cardiac surgery & $1(1)$ \\
\hline & Emergency medicine & $6(6)$ \\
\hline & General surgery & $6(6)$ \\
\hline & Internal medicine & $57(58)$ \\
\hline & Neurology & $2(2)$ \\
\hline & Pediatrics & $15(15)$ \\
\hline & Respirology/respiratory medicine & $6(6)$ \\
\hline \multirow[t]{3}{*}{ Type of institution(s) $(n=98)^{*}$} & Academic/teaching hospital & $86(88)$ \\
\hline & Community hospital (urban, suburban, and/or rural) & $32(33)$ \\
\hline & Affiliated with an organ donation organization & $5(5)$ \\
\hline \multirow[t]{2}{*}{ Formal role as donation physician } & Yes & $31(29)$ \\
\hline & No & $75(71)$ \\
\hline \multirow{2}{*}{ Work in centre where transplants are performed } & Yes & $58(55)$ \\
\hline & No & $48(45)$ \\
\hline
\end{tabular}

*Respondents could select $>1$ response. ICU $=$ intensive care unit.

following NDD might be related to "cultural issues" faced by immigrants and non-white families (ESM eTable 3).

Mitigation strategies for resolving disagreements and misunderstandings

The most commonly chosen strategies to address requests for continued organ support after NDD were delay of one to three days to allow families to accept the declaration (49/100, 49\%), consultation with another physician within the hospital $(55 / 101,54 \%)$, and consultation with spiritual care services $(41 / 100,41 \%)$ (Table 6). Respondents who had personal experience with a request were more likely to indicate they would not provide an ancillary blood flow test $(P=0.004)$ and would not consult with their hospital 
Table 2 Frequency of experience with family requests for continued organ support following NDD* $(n=106)$

\begin{tabular}{|c|c|c|}
\hline Survey question & Response categories & No. $(\%)$ \\
\hline \multirow{4}{*}{$\begin{array}{l}\text { Over the course of your career, how many times have you determined } \\
\text { death using neurologic criteria or cared for a patient after the } \\
\text { determination of death using neurologic criteria? }\end{array}$} & $0-5$ patients & $5(5)$ \\
\hline & 5-10 patients & $19(18)$ \\
\hline & $11-20$ patients & $15(14)$ \\
\hline & $>20$ patients & $67(63)$ \\
\hline \multirow{5}{*}{$\begin{array}{l}\text { In the past } 2 \text { years, how many times have you determined death } \\
\text { using neurologic criteria or cared for a patient after the } \\
\text { determination of death using neurologic criteria? }\end{array}$} & 0 patients & $1(1)$ \\
\hline & $1-3$ patients & $28(26)$ \\
\hline & 4-6 patients & $33(31)$ \\
\hline & $7-10$ patients & $19(18)$ \\
\hline & More than 10 patients & $25(24)$ \\
\hline \multirow{4}{*}{$\begin{array}{l}\text { In the past } 2 \text { years, how often have you personally interacted with a } \\
\text { family that requested continued organ support and/or refused } \\
\text { withdrawal of organ support following the determination of death } \\
\text { using neurologic criteria? }\end{array}$} & 0 times & $51(48)$ \\
\hline & 1-2 times & $42(40)$ \\
\hline & $3-4$ times & $3(3)$ \\
\hline & $\geq 5$ times & $10(9)$ \\
\hline
\end{tabular}

*Frequency of experience with NDD in the past two years and frequency of family requests for continued organ support following NDD within the past two years is associated, $P=0.02$. NDD = neurologic determination of death.

Table 3 Frequency of experience with family requests for continued organ support across provinces

\begin{tabular}{llllll}
\hline Province & \multicolumn{2}{l}{ Frequency of requests for continued organ support after NDD } & \\
\cline { 2 - 5 } & 0 times & $1-2$ times & $3-4$ times & 2 & \\
\hline Alberta & 8 & 8 & 0 & 1 & $17(16)$ \\
British Columbia & 5 & 1 & 1 & 2 & $9(8)$ \\
Manitoba & 1 & 4 & 0 & 0 & $5(5)$ \\
Newfoundland and Labrador & 1 & 0 & 0 & 0 & $1(1)$ \\
Nova Scotia & 4 & 1 & 0 & 4 & $7(7)$ \\
Ontario & 23 & 23 & 2 & 1 & $52(49)$ \\
Québec & 9 & 2 & 0 & 0 & $12(11)$ \\
Saskatchewan & 0 & 3 & 0 & $10(9)$ & $3(3)$
\end{tabular}

Two-sided Fisher's exact test $P=0.15$ (i.e., no significant association between province and frequency of family requests for continued organ support after NDD)

$\mathrm{NDD}=$ neurologic determination of death

bioethics service $(P=0.004)$ if they encountered a similar experience again.

In the qualitative analysis, physicians who had experienced requests for continued organ support after NDD suggested that ancillary testing was unlikely to help with resolution in situations where families were "waiting for a miracle" or could not accept that death had occurred (ESM eTable 4). As one participant described, “...to a certain extent to get any type of ancillary testing became kind of a moot point because they [the family] were not... I could've done fifty ancillary tests, they were not going to accept that [the patient] had a fatal prognosis," (Interview \#7). Providing additional information about NDD was felt to have little impact in situations where families were perceived as unable to accept the patient's death at all.

Participants also explained that while clinical ethics services were "helpful to talk to", they did not offer new approaches for resolving disputes, prolonged the length of the dispute through ongoing discussions, and were perceived by families in some cases as representing hospital interests (ESM eTable 4). 
Table 4 Threats of legal action related to family requests for continued organ support following NDD

\begin{tabular}{|c|c|c|}
\hline Question & $\begin{array}{l}\text { Response } \\
\text { categories }\end{array}$ & $\begin{array}{l}\text { No. } \\
(\%)\end{array}$ \\
\hline \multirow{3}{*}{$\begin{array}{l}\text { In your personal experience, has a family request for continued organ support after NDD ever resulted in a threat of } \\
\text { legal action? }(n=49)\end{array}$} & Yes & $26(53)$ \\
\hline & No & $19(39)$ \\
\hline & Not sure & $4(8)$ \\
\hline \multirow[t]{2}{*}{ If yes, how many times? $(n=18)$} & 1 & $12(67)$ \\
\hline & $>1$ & $6(33)$ \\
\hline \multirow{3}{*}{$\begin{array}{l}\text { In your personal experience, has a family request for continued organ support after NDD ever resulted in a tribunal } \\
\text { application or hearing (e.g., Consent and Capacity Board, dispute resolution)? }(n=50)\end{array}$} & Yes & $12(24)$ \\
\hline & No & $36(72)$ \\
\hline & Not sure & $2(4)$ \\
\hline \multirow[t]{2}{*}{ If yes, how many times? $(n=8)$} & 1 & $5(63)$ \\
\hline & $>1$ & $3(37)$ \\
\hline \multirow[t]{3}{*}{ In your personal experience, have any of these experiences ever resulted in legal action (i.e., court case)? $(n=50)$} & Yes & $9(18)$ \\
\hline & No & $38(76)$ \\
\hline & Not sure & $3(6)$ \\
\hline \multirow[t]{2}{*}{ If yes, how many times? $(n=8)$} & 1 & $7(88)$ \\
\hline & $>1$ & $1(12)$ \\
\hline
\end{tabular}

NDD = neurologic determination of death.

Table 5 Comparison of perceived reasons for family requests for continued organ support following NDD

\begin{tabular}{|c|c|c|}
\hline Perceived cause & $\begin{array}{l}\text { No. }(\%) \text { without personal experience of request } \\
\text { for continuation of organ support } \\
(n=51)\end{array}$ & $\begin{array}{l}\text { No. }(\%) \text { with personal experience of request } \\
\text { for continuation of organ support } \\
(n=50)\end{array}$ \\
\hline $\begin{array}{l}\text { Desire for a miracle or inability to accept death } \\
\text { at all }\end{array}$ & $24(47)$ & $32(64)$ \\
\hline $\begin{array}{l}\text { Mistrust in validity of tests used to establish } \\
\text { death by neurologic criteria }\end{array}$ & $4(8)$ & $3(6)$ \\
\hline Mistrust of medical system & $1(2)$ & $1(2)$ \\
\hline $\begin{array}{l}\text { Religious objections to concept of neurologic } \\
\text { criteria for determination of death }\end{array}$ & 19 (37) & $11(22)$ \\
\hline Other* & $3(6)$ & $3(6)$ \\
\hline
\end{tabular}

*Includes: "combination of all of the above", "there is no one reason", "poor communication between staff and families", "family not interested, no specific reason", "none of the above", "request for time for family visits". NDD = neurologic determination of death.

\section{Additional emergent themes from interviews}

During open-ended and exploratory parts of the interviews, participants were encouraged to discuss what they felt was most pertinent to the issue of family requests for continued organ support following NDD. Discussion themes included: the need for a clear legal definition of criteria for determining death in Canada, the idea that requests for organ support following NDD may be part of a broader trend of increasing requests for continued life-support of patients with non-recoverable injuries, and the need for a more assertive approach in communication to relieve guilt surrounding end of life decisions (ESM eTable 5). Finally, two participants discussed cases in which families seemed to mount a resistance to NDD over the course of clinical care, describing families as "initially on board" but later disputing NDD (ESM eTable 5). 
Table 6 Strategies for resolving requests for continued organ support after NDD

\begin{tabular}{|c|c|c|c|c|}
\hline Strategy & & $\begin{array}{l}\text { No. }(\%) \text { without } \\
\text { personal experience } \\
\text { of request for continuation } \\
\text { of organ support }\end{array}$ & $\begin{array}{l}\text { No. }(\%) \text { with personal } \\
\text { experience of request } \\
\text { for continuation of } \\
\text { organ support }\end{array}$ & $P$ value \\
\hline \multirow[t]{5}{*}{ Give the family $1-3$ days to accept declaration } & Would not do this & $1(2)$ & $1(2)$ & \multirow[t]{5}{*}{0.60} \\
\hline & Might do this & $7(14)$ & $8(16)$ & \\
\hline & Would probably do this & $18(35)$ & $16(33)$ & \\
\hline & \multirow[t]{2}{*}{ Would definitely do this } & $25(49)$ & $24(49)$ & \\
\hline & & $n=51$ & $n=49$ & \\
\hline \multirow[t]{5}{*}{ Give the family $>3$ days to accept declaration } & Would not do this & $25(50)$ & $21(45)$ & \multirow[t]{5}{*}{0.28} \\
\hline & Might do this & $9(18)$ & $16(34)$ & \\
\hline & Would probably do this & $15(30)$ & $5(11)$ & \\
\hline & \multirow[t]{2}{*}{ Would definitely do this } & $1(2)$ & $5(11)$ & \\
\hline & & $n=50$ & $n=47$ & \\
\hline \multirow[t]{5}{*}{ Option of ancillary blood flow test* } & Would not do this & $3(6)$ & $18(37)$ & \multirow[t]{5}{*}{$0.004 *$} \\
\hline & Might do this & $14(27)$ & $10(20)$ & \\
\hline & Would probably do this & $13(25)$ & $7(14)$ & \\
\hline & \multirow[t]{2}{*}{ Would definitely do this } & $21(41)$ & $14(29)$ & \\
\hline & & $n=51$ & $n=49$ & \\
\hline \multirow[t]{5}{*}{ Option of other ancillary tests } & Would not do this & $18(37)$ & $29(60)$ & \multirow[t]{5}{*}{0.29} \\
\hline & Might do this & $16(33)$ & $10(21)$ & \\
\hline & Would probably do this & $8(16)$ & $3(6)$ & \\
\hline & \multirow[t]{2}{*}{ Would definitely do this } & $7(14)$ & $6(13)$ & \\
\hline & & $n=49$ & $n=48$ & \\
\hline \multirow[t]{5}{*}{ Additional physician consult-within hospital* } & Would not do this & $0(0)$ & $5(10)$ & \multirow[t]{5}{*}{$0.01 *$} \\
\hline & Might do this & $4(8)$ & $15(30)$ & \\
\hline & Would probably do this & $17(33)$ & $5(10)$ & \\
\hline & \multirow[t]{2}{*}{ Would definitely do this } & $30(59)$ & $25(50)$ & \\
\hline & & $n=51$ & $n=50$ & \\
\hline \multirow[t]{5}{*}{ Additional physician consult—external physician* } & Would not do this & $9(18)$ & $30(61)$ & \multirow[t]{5}{*}{$0.003 *$} \\
\hline & Might do this & $19(38)$ & $13(27)$ & \\
\hline & Would probably do this & $13(26)$ & $3(6)$ & \\
\hline & \multirow[t]{2}{*}{ Would definitely do this } & $9(18)$ & $3(6)$ & \\
\hline & & $n=50$ & $n=49$ & \\
\hline \multirow[t]{5}{*}{ Consult with bioethics service* } & Would not do this & $2(4)$ & $20(42)$ & \multirow[t]{5}{*}{$0.004 *$} \\
\hline & Might do this & $13(25)$ & $13(27)$ & \\
\hline & Would probably do this & $15(29)$ & $5(10)$ & \\
\hline & \multirow[t]{2}{*}{ Would definitely do this } & $21(41)$ & $10(21)$ & \\
\hline & & $n=51$ & $n=48$ & \\
\hline \multirow[t]{5}{*}{ Consult with spiritual services } & Would not do this & $3(6)$ & $5(10)$ & \multirow[t]{5}{*}{0.56} \\
\hline & Might do this & $8(16)$ & $12(24)$ & \\
\hline & Would probably do this & $17(33)$ & $14(29)$ & \\
\hline & \multirow[t]{2}{*}{ Would definitely do this } & $23(45)$ & $18(37)$ & \\
\hline & & $n=51$ & $n=49$ & \\
\hline
\end{tabular}

*Statistically significant difference between those with experience with family requests for continued organ support compared with those with no experience. $\mathrm{NDD}=$ neurologic determination of death. 


\section{Discussion}

This mixed-methods study is the first to broadly engage Canadian intensivists about their experiences with requests for continued organ support following NDD. Physicians with and without personal experience of the issue were willing to complete the survey and share opinions through interviews. The demographic profile of our respondents closely matches those recently reported by the Canadian Medical Association for the specialty of critical care. ${ }^{38}$ Our results illustrate that requests for continued support following NDD occur in Canada, with more than half $(52 \%)$ of survey respondents from across the country indicating they had experienced some form of this issue within the past two years. Lewis et al. reported a similar prevalence in a survey of American neurologists. ${ }^{28}$ Together, these surveys suggest that requests for continued organ support following NDD are widespread throughout the United States and Canada. Evidence from in-depth interviews shows perceptions of what constitutes a request for continued support following NDD ranges from appeals for time for family to gather before ventilator removal to formal disagreement with the concept of NDD; this ambiguity may contribute to an overestimation of conflict. Differences in case presentation also underscore the need for multifaceted and contextual approaches to mitigation.

The emergent qualitative theme of the perceived need for a national definition of death highlights the added value of our study in the Canadian context. Many participants voiced hope that legal clarification of the definition of death would help to reduce the incidence of family requests for continued support after NDD. At present, the legal definition of death in Canada is "according to accepted medical practice". ${ }^{1,20}$ Manitoba offers the single exception, with the explicit definition of "irreversible cessation" of "brain function" included in the Vital Statistics Act. ${ }^{39}$ Despite this definition, we found physicians from Manitoba had experience with family requests for continued organ support following NDD. In addition, Lewis et al. ${ }^{28,29}$ provide evidence that requests for continued organ support after NDD persist in the context of the Uniform Determination of Death Act, ${ }^{40}$ which enacted NDD as a legal basis for determining death across the United States in 1980. These findings imply family requests for continued organ support are likely to continue in Canada even if the legal definition of death is clarified.
Consequently, it may be more beneficial to clarify practical and fair legal processes for religious and moral accommodations rather than attempting to circumvent requests altogether.

Our findings establish that within a sample of Canadian physicians experiencing requests for continued organ support following NDD, only $24 \%$ of cases moved to formal dispute resolution (e.g., through a local judge or special ethics board), and $18 \%$ proceeded to formal court cases. Although the absolute number is small, court cases surrounding conflicts over the declaration of death tend to be sensationalized in the media and engage large numbers of bedside staff as well as hospital administration. As a result, these situations are highly taxing for physicians, families, hospitals, and communities involved. Though legal clarification of the definition of death in Canada may not reduce the number of requests for continued support after NDD, it may help to prevent rare, but distressing, prolonged legal cases. Qualitative themes including underlying tensions between shared decision-making and paternalism, the potential influence of increased misinformation and mistrust in medicine, and the perception that those with lived experience of being religious or cultural minorities may struggle with end of life scenarios suggest that, in addition to legal clarification, broader and more complex strategies for ongoing social engagement surrounding the definition of death and the limits of life sustaining therapies are required.

Finally, our results show that physicians with experience with families requesting continued organ support after NDD were less likely to suggest ancillary testing, consultation with external specialists, and ethics consultations as approaches for dispute resolution. Though we did not explicitly ask respondents the maximum amount of time acceptable to provide families prior to discontinuing organ support, $47 \%$ were uncomfortable with providing more than three days. These findings are supported by in-depth interviews and indicate that while academic discussion is ongoing about how best to manage these difficult clinical situations, ${ }^{41}$ there is growing practical expertise in what not to do. We suggest further consensus-building, which also solicits input from family members to outline possible approaches for Canadian clinicians faced with requests for continued organ support following NDD. 


\section{Limitations}

While providing a useful foray into a topic yet unexplored in Canada, this survey includes a number of limitations. First, our response rate was $25 \%$. Though this is on par with the $21 \%$ response rate of a similar survey of American neurologists, ${ }^{28}$ our findings may not be representative of all Canadian critical care physicians. Additionally, participation rate in interviews was low and we did not reach thematic saturation; nonetheless interviews provide nuance and depth to our survey findings. It is important to note that this is a survey of intensivists about perceptions of family beliefs and motivators for decision-making, not a survey of families who have objected to discontinuation of organ support after NDD. The impact of this issue on nurses and other allied health professionals was not explored. This study focused on physician perspectives and thus did not engage with members of the public or allied health professionals as part of its design.

\section{Conclusions}

This survey provides the first description of Canadian intensive care physicians' experiences with family requests for continued organ support following NDD. Family requests for continued somatic support following NDD were encountered by $52 \%$ of our sample and ranged from requests for time for family members to gather, to denial of death. Mitigation strategies should consider the multifaceted social contexts of these scenarios rather than focus only on lack of information or family understanding. Further research should seek to understand requests for continued organ support after NDD from family perspectives and to elucidate practical suggestions for ensuring high quality end of life care in these situations.

Acknowledgements We are grateful for the support of the Canadian Critical Care Society in providing access to their mailing list and for encouraging member participation. We thank all participants, both anonymous and in interviews, for participating in discussions about this unique clinical scenario.

Disclosures The authors declare no conflicts of interest.

Funding statement No funding was received for the conduct of this research project or for the preparation or submission of this manuscript.

Editorial responsibility This submission was handled by Dr. Sangeeta Mehta, Associate Editor, Canadian Journal of Anesthesia. 


\section{Appendix A: Initial question domains for self- administered survey of Canadian critical care physicians}

Survey domain

Demographics

Extent of experience with NDD

Frequency of experiences with families requesting continued organ support following a declaration of death using neurologic criteria

Perceived reasons for family difficulty
Potential specific elements/questions

Age and gender: $\mathrm{M} / \mathrm{F}$

Primary province of practice

Number of years clinical experience in ICU (1-5 years, 6-10 years, 11-15 years, $16+$ years)

Base specialty

Credentials (MD, MSc, PhD, FRCP/SC, DRCPC)

Pediatrics, Adult, or Both practice

Practice Setting: Academic / Large Community / Small Community

Size of ICU (\# beds)

How many weeks of ICU do you do per year on average over the last 3 years of your practice?

Current role (Staff physician, Resident, Associate)

In the past two years, how many times have you determined death by neurological criteria (declared brain death) or cared for a patient after declaration of death using neurologic criteria?

( 0 cases, 1-5 cases, 6-10 cases, $11+$ cases)

Over the course of your career, how many times have you determined death by neurological criteria (declared brain death) or cared for a patient after this declaration of death?

(never ( 0 times), rarely ( $<5$ cases), sometimes (5-10 cases), often (10-20 cases $)$, frequently $(20+$ cases $))$

In the past year, how often have you personally interacted with a family that requested continued organ support and/or refused withdrawal of organ support following a determination of death using neurological criteria?

(0 times*, 1-2, 3-4, 5-6, 6+ times, )

*If the respondent selects 0 times, they should be directed to a series of hypothetical questions about experiences with families requesting continued organ support following a declaration of death using neurologic criteria [question set A below]

If you have personal experience with a family (or families) that requested continued organ support and/or refused withdrawal of organ support following a determination of death using neurological criteria, what, in your opinion, has been the number one reason for this response?

Check all that apply:

(Religious objections to concept of NDD, mistrust of medical system, mistrust in validity of tests used to establish NDD, desire for a miracle/ inability to accept death at all, I don't know, other: please describe) 
continued

Survey domain

Strategies employed to mitigate situation

Experience with legal action/CCB cases

Interest in participation in telephone interview organ support after NDD
Potential specific elements/questions

During your experiences in the past year with families who requested continued organ support and/or refused withdrawal of organ support following a declaration of death using neurological criteria, how often did you use any of the following strategies to attempt to overcome this challenge:

$>$ Giving the family brief time (e.g. 1-3 days) to accept the declaration of death (never, in some cases, in most cases, in every case)

$>$ Giving the family prolonged time (e.g. greater than 3 days) to accept the declaration of death (never, in some cases, in most cases, in every case)

$>$ Providing the option of ancillary brain blood flow tests to help the family accept NDD (never, in some cases, in most cases, in every case)

$>$ Providing the option of other ancillary tests to help the family accept NDD (never, in some cases, in most cases, in every case)

$>$ Providing the option of an additional physician opinion to confirm NDD (never, in some cases, in most cases, in every case)

$>$ Consulting with a hospital bioethics service (never, in some cases, in most cases, in every case)

$>$ Offering the possibility of withdrawal of body/somatic support without an acceptance of NDD (never, in some cases, in most cases, in every case)

$>$ Other (please describe) (never, in some cases, in most cases, in every case)

If you have personal experience with a family (or families) that requested continued organ support and/or refused withdrawal of organ support following a determination of death using neurological criteria, has this ever resulted in threats of legal action? (yes, no, not sure)

(If yes, how many times: 1, 2, 3+)

If you have personal experience with a family (or families) that requested continued organ support and/or refused withdrawal of organ support following a determination of death using neurological criteria, has this ever resulted in legal action? (yes, no, not sure)

(If yes, how many times: 1, 2, 3+)

If you have personal experience with a family (or families) that requested continued organ support and/or refused withdrawal of organ support following a determination of death using neurological criteria, has this ever resulted in a Consent and Capacity Board hearing or application? (yes, no, not sure)

(If yes, how many times: 1, 2, 3+)

Open-ended thoughts on responses to family requests for continued

What are your thoughts on how physicians can manage/respond to cases where families' request continued organ support and/or refuse to withdraw organ support following a determination of death using neurological criteria?

(open-ended question)

Any other thoughts you wish to share about this topic?

(open-ended question)

Are you interested in participating in a brief (20-30 min) telephone interview to discuss your experiences in more detail with our study team? (yes - please provide contact info, no) 
continued

\begin{tabular}{ll}
\hline Survey domain & Potential specific elements/questions
\end{tabular}

Question Set A - if respondent has had no interactions with families requesting continued organ support after NDD

What, in your opinion, do you think would be the number one reason that families might request continued organ support and/or refuse to withdraw organ support following the declaration of death using neurologic criteria?(Religious objections to concept of NDD, mistrust of medical system, mistrust in validity of tests used to establish NDD, desire for a miracle/inability to accept death at all, other: please describe)

If, during your clinical work, you came across a family that requested continued organ support and/or refused withdrawal of organ support following a determination of death using neurological criteria, which of the following strategies do you think you would be most likely to employ to overcome this challenge?

$>$ Give the family brief time (e.g. 1-3 days) to accept the declaration of death (would not do this, might do this, would probably do this, would definitely do this)

$>$ Give the family prolonged time (e.g. greater than 3 days) to accept the declaration of death (would not do this, might do this, would probably do this, would definitely do this)

$>$ Provide the option of ancillary brain blood flow tests to help the family accept NDD (would not do this, might do this, would probably do this, would definitely do this)

$>$ Provide the option of other ancillary tests to help the family accept NDD (never, in some cases, in most cases, in every case)

$>$ Provide the option of an additional physician opinion to confirm NDD (would not do this, might do this, would probably do this, would definitely do this)

$>$ Consult with a hospital bioethics service (would not do this, might do this, would probably do this, would definitely do this)

$>$ Offer the possibility of withdrawal of body/somatic support without an acceptance of NDD (would not do this, might do this, would probably do this, would definitely do this)

$>$ Other (please describe) (would not do this, might do this, would probably do this, would definitely do this)

\section{Appendix B: Copy of final electronic self-administered survey as administered to Canadian critical care physicians}


1. Do you practice critical care in Canada (can be an educational license or as a staff intensivist)?

Yes / No

\title{
PARTICIPANT INFORMATION SHEET AND INFORMED CONSENT FORM
}

\section{Study Title:}

Canadian physician experiences of situations in which families object to discontinuation of organ support after the determination of death using neurological criteria

\author{
Co-Investigators: \\ Amanda van Beinum, $\mathrm{MSc}, \mathrm{PhD}(\mathrm{c})$ \\ Carleton University, Dept. Sociology \& Anthropology \\ Children's Hospital of Eastern Ontario Research Institute, Ottawa ON \\ avanbeinum@cheo.on.ca
}

\author{
Andrew Healey, MD FRCPC \\ Staff Intensivist, Medical Director of Critical Care \\ William Osler Health System \\ Associate Clinical Professor, Division of Emergency Medicine \\ Department of Medicine, McMaster University \\ 905-494-2120, extension 57486 \\ andrew.healey@williamoslerhs.ca
}

\section{Introduction}

You are being asked to take part in a research study. In order to decide whether or not you want to be a part of this research study, you should understand what is involved. Participation in this study is voluntary.

\section{Background and Purpose}

Neurological determination of death (NDD), also known as "brain death" is part of the legally accepted medical practice that can be used to determine death both in Canada and around the world. In some cases, accepting that a loved one has died while they remain on a ventilator and supported by various technologies can be difficult for families. Physicians encounter this to varying degrees in their practice across Canada. There are two current legal challenges to the neurological determination of death that are active in the court systems. This prompted a need to understand the physician experience in working with families that request continued organ support and/or refuse withdrawal of organ support following a determination of death using neurological criteria.

This study attempts to describe the current physician experience and what physicians who have not encountered this in practice might consider doing.

\section{Study Design}

If you consent to this study, you will be directed to a website where an electronic survey is hosted and asked to complete a series of questions. This should take you approximately $\mathbf{1 0}$ minutes. You will have an opportunity to volunteer to be interviewed by recorded phone call at the conclusion of the electronic survey. A selected portion of volunteers will be contacted. Once you have been contacted or the decision has been made not to contact you, your contact information will be destroyed. During the phone interview, you will be reminded that you are being recorded so that the information can be utilized at a later date.

\section{Questions About the Study}

If you have any questions, concerns or would like to speak to the study team for any reason, please call: Dr. Andrew Healey at 1-905-494-2120, extension 57486.

If you have any questions about your rights as a research participant or have concerns about this 
study, call Ronald Heslegrave, Ph.D., Chair of the William Osler Health System Research Ethics Board (REB) at 905-494-2120 ext. 50448. The REB is a group of people who oversee the ethical conduct of research studies. These people are not part of the study team. Everything that you discuss will be kept confidential.

2. Consent

I have read and understood the information above and I agree to take part in this study. I know that I may leave this study at any time.

Yes - I agree to participate

No - I decline to participate in this study.

\section{DEMOGRAPHICS}

3. 3. What is your gender?

Male

Prefer not to say

Female

Other (please specify):

4. 4. How old are you?

25-34

55-64

$35-44$

$65+$

$45-54$

Other (please specify):

5. In which province or territory do you primarily practice?

$\begin{array}{ll}\text { Newfoundland and Labrador } & \text { Saskatchewan } \\ \text { Nova Scotia } & \text { Alberta } \\ \text { Prince Edward Island } & \text { British Columbia } \\ \text { New Brunswick } & \text { Yukon } \\ \text { Quebec } & \text { Northwest Territories } \\ \text { Ontario } & \text { Nunavut }\end{array}$

Manitoba

6. How many years of staff intensivist clinical experience have you had in critical care (ICU) medicine?

0 years

$1-5$ years

$11-15$ years

16-20 years

6-10 years

More than 20 years

7. What is your base specialty? (Check all that apply) Internal Medicine

Emergency Medicine

Neurology

General Surgery

Anesthesia

Neurosurgery

Pediatrics

Other (please specify)

8. Select all credentials that apply to you.

MD

MSc

FRCPC or FRCSC

DRCPC

$\mathrm{PhD}$

Other (please specify)

9. To which population do you provide critical care?

Adult (age 16 or 18 years of age or older)

Pediatric (age 16 or 18 years of age or younger)

Both

10. In which type(s) of institutions do you primarily work? [Select all that apply]

Academic / teaching hospital

Urban community hospital

Suburban community hospital

Rural community hospital

Organ donation organization

Other (please specify) 
11. In your primary practice setting, how many ICU beds are there in your hospital?
Less than 12
36-48
$12-24$
More than 48

24-36

12. How many weeks of critical care service do you provide per year (average over the last three years of your practice)?

Less than $8 \quad 16-20$

8-12 20-24

12-16 More than 24

13. State your current role in critical care medicine practice.

Staff Critical Care Physician Critical Care Resident, Base

Critical Care Resident, Base specialty certification pending

specialty completed Clinical Associate

Other (please specify)

14. Do you have any formal role as a donation physician?

Yes

No

15. Do you work in a transplant centre (where transplants are performed)?

Yes

No

\section{EXTENT OF EXPERIENCE WITH NEUROLOGICAL DETERMINATION OF DEATH (NDD)}

Please describe only YOUR PERSONAL experiences NOT those you may have heard about. $\mathrm{OK}$

16. Over the course of your career, how many times have you determined death using neurological criteria or cared for a patient after the determination of death using neurological criteria?
0 patients
11-20 patients
$1-5$ patients
$20+$ patients
5-10 patients
Other (please specify)

17. In the past two years, how many times have you determined death using neurological criteria or cared for a patient after the determination of death using neurological criteria? 0 (zero) patients. I have not encountered a patient who met criteria for NDD in the past year. 4-6 patients

7-10 patients 1-3 patients

More than 10 patients

Other (please specify)

18. In the past two years, how often have you personally interacted with a family that requested continued organ support and/or refused withdrawal of organ support following the determination of death using neurological criteria?
0 times
5-6 times
1-2 times
More than 6 times
3-4 times

\section{NO PERSONAL EXPERIENCE WITH FAMILIES REQUESTING CONTINUED ORGAN SUPPORT FOLLOWING NDD}

You have indicated you have no personal experience with a family (or families) that requested 
continued organ support and/or refused withdrawal of organ support following a determination of death using neurological criteria (referred to herein as families).

These questions are about your opinions about what you think you might do should this situation ever arise in your practice.

$\mathrm{OK}$

19. What, in your opinion, would you think has been the number one reason for requests for continued organ support and/or refusal of withdrawal of organ support following the determination of death using neurological criteria?

Religious objections to concept of neurological criteria for determination of death

Mistrust of medical system

Mistrust in validity of tests used to establish death by neurological criteria

Desire for a miracle or inability to accept death at all

I don't know

Other (please specify)

20. If, during your clinical work, you came across a family that requested continued organ support and/or refused withdrawal of organ support following the determination of death using neurological criteria, how likely would you be to employ the following strategies to overcome this challenge before withdrawing support?

\begin{tabular}{|l|l|l|l|l|}
\hline & $\begin{array}{l}\text { Would not } \\
\text { do this }\end{array}$ & $\begin{array}{l}\text { Might do } \\
\text { this }\end{array}$ & $\begin{array}{l}\text { Would } \\
\text { probably do } \\
\text { this }\end{array}$ & $\begin{array}{l}\text { Would } \\
\text { definitely } \\
\text { do this }\end{array}$ \\
\hline $\begin{array}{l}\text { Giving the family brief time (e.g. 1- } \\
\text { 3 days) }\end{array}$ & & & & \\
\hline $\begin{array}{l}\text { Giving the family prolonged time } \\
\text { (i.e. > 3 days) }\end{array}$ & & & & \\
\hline $\begin{array}{l}\text { Providing option of ancillary brain } \\
\text { blood flow tests to help family } \\
\text { understand }\end{array}$ & & & & \\
\hline $\begin{array}{l}\text { Providing option of other ancillary } \\
\text { tests (e.g. EEG) to help family } \\
\text { understand }\end{array}$ & & & & \\
\hline $\begin{array}{l}\text { Providing option of an additional } \\
\text { physician opinion from within the } \\
\text { institution }\end{array}$ & & & & \\
\hline $\begin{array}{l}\text { Providing option of an additional } \\
\text { physician opinion from outside the } \\
\text { institution }\end{array}$ & & & & \\
\hline $\begin{array}{l}\text { Consulting with hospital bioethics } \\
\text { service }\end{array}$ & & & & \\
\hline $\begin{array}{l}\text { Consulting with spiritual services } \\
\text { (within hospital) }\end{array}$ & & & & \\
\hline $\begin{array}{l}\text { Offering possibility of withdrawal } \\
\text { of organ support without } \\
\text { acceptance of NDD }\end{array}$ & & & & \\
\hline Other (please specify) & & & & \\
\hline
\end{tabular}

21. What are your thoughts on how physicians can manage/respond to cases where families request continued organ support and/or refuse to withdraw organ support following a determination of death using neurological criteria?

22. Are you interested in participating in a brief (20-30 minute) telephone interview to discuss your thoughts and experiences in more detail with our study team?

If YES, click here and you will be taken to a separate, secure website to enter your contact information to allow investigators to contact you. 
The contact info you provide can NOT be linked to your survey answers in any way.

Yes, I'd like to participate in an interview

No, I'm not interested in an interview at this time

23. Thank you for your participation in this study. If there is anything else you wish to share, please feel free to do so.

\section{PERSONAL EXPERIENCE WITH FAMILIES REQUESTING CONTINUED ORGAN SUPPORT FOLLOWING NDD}

You have indicated you have personal experience with a family (or families) that requested continued organ support and/or refused withdrawal of organ support following a determination of death using neurological criteria.

Please answer the following question based on your personal experiences in these situations. $\mathrm{OK}$

24. What, in your opinion, has been the number one reason for requests for continued organ support and/or refusal of withdrawal of organ support following the determination of death using neurological criteria?

Religious objections to concept of neurological criteria for determination of death Mistrust of medical system

Mistrust in validity of tests used to establish death by neurological criteria

Desire for a miracle or inability to accept death at all

I don't know

Other (please specify)

25. How often did you use any of the following strategies to attempt to overcome this challenge?

\begin{tabular}{|l|l|l|l|l|}
\hline & Never & $\begin{array}{l}\text { In some } \\
\text { cases }\end{array}$ & In most cases & $\begin{array}{l}\text { In every } \\
\text { case }\end{array}$ \\
\hline $\begin{array}{l}\text { Giving the family brief time (e.g. 1- } \\
\text { 3 days) }\end{array}$ & & & & \\
\hline $\begin{array}{l}\text { Giving the family prolonged time } \\
\text { (i.e. > 3 days) }\end{array}$ & & & & \\
\hline $\begin{array}{l}\text { Providing option of ancillary brain } \\
\text { blood flow tests to help family } \\
\text { understand }\end{array}$ & & & & \\
\hline $\begin{array}{l}\text { Providing option of other ancillary } \\
\text { tests (e.g. EEG) to help family } \\
\text { understand }\end{array}$ & & & & \\
\hline $\begin{array}{l}\text { Providing option of an additional } \\
\text { physician opinion from within the } \\
\text { institution }\end{array}$ & & & & \\
\hline $\begin{array}{l}\text { Providing option of an additional } \\
\text { physician opinion from outside the } \\
\text { institution }\end{array}$ & & & & \\
\hline $\begin{array}{l}\text { Consulting with hospital bioethics } \\
\text { service }\end{array}$ & & & & \\
\hline $\begin{array}{l}\text { Consulting with spiritual services } \\
\text { (within hospital) }\end{array}$ & & & & \\
\hline $\begin{array}{l}\text { Offering possibility of withdrawal } \\
\text { of organ support without } \\
\text { acceptance of NDD }\end{array}$ & & & & \\
\hline
\end{tabular}




\begin{tabular}{|l|l|l|l|l|}
\hline $\begin{array}{l}\text { Other (please specify what you did } \\
\text { and how frequently) }\end{array}$ & & & & \\
\hline & & & & \\
\hline
\end{tabular}

26. If you used any of these strategies, please describe which (if any) helped resolve the challenge, and why?

27. In your personal experience, have any of these situations (family requests for continued organ support and/or refusal of withdrawal of support following a determination of death using NDD) ever resulted in a tribunal application or hearing (e.g. Consent and Capacity Board)?

Yes Not sure

No If yes, how many times?

28. In your personal experience, have any of these situations ever resulted in threats of legal action?

Yes

No

Not sure

If yes, how many times?

29. In your personal experience, have

any of these experiences ever

resulted in legal action (i.e. to court)?

Yes

No

Not sure

If yes, how many times?

30. What are your thoughts on how physicians can manage/respond to cases where families request continued organ support and/or refuse to withdraw organ support following a determination of death using neurological criteria?

31. Are you interested in participating in a brief (20-30 minute) telephone interview to discuss your thoughts and experiences in more detail with our study team?

If YES, click here and you will be taken to a separate, secure website to enter your contact information to allow investigators to contact you.

The contact info you provide can NOT be linked to your survey answers in any way.

Yes, I'd like to participate in an interview

No, I'm not interested in an interview at this time

32. Thank you for your participation in this study. If there is anything else you wish to share, please feel free to do so.

\section{Appendix C: Copy of interview guide for semi- structured interviews with physicians}


Physician Interviews - Experiences with Family Requests for Continued Life-Support after NDD (v. March 14, 2019)

\section{INTRODUCTION}

- Thank you for answering the online survey and setting aside the time to speak to me today about your experiences

- Interview should take about 30-40 minutes

- Value of participation - to get more detailed and contextual information about this phenomenon of families requesting continued life-support after NDD

- Reminder that you are being recorded for accuracy of our conversation

- Reminder that no identifying information will be used in any analysis or resulting publication

- Reminder that you can choose not to answer certain questions or to end the conversation at any time

- Reminder that I don't have access to the responses they entered online since that survey was anonymous and cannot be linked with their name (apologies if some of the questions are repeated, but this is a chance to provide more detail)

\section{Q1 What is your experience with declaring death using neurologic criteria?}

- For background info to provide context to answers:

o Practice specialty

o Number of years of service

- Experiences with organ donation (frequency?)

o Type of hospital you work in (community, university, etc.)

Q2 Do you have any personal experience(s) with a family or families that requested continued organ support and/or refused withdrawal of organ support following a declaration of death using neurologic criteria?

- If YES: please describe the (most memorable) case

o When did you realize there was a conflict over NDD? How soon after the NDD diagnosis did the conflict appear? What were the first signs of conflict? How did the family make the request for continued support?

o What is your sense of why the family had difficulty with the NDD declaration?

o Who was involved in the case? (Clinical \& hospital services)

o Did you ever offer the family ancillary testing? If yes, which ones?

o What was the outcome of the case/how did it end? (clinical, emotional, policy?) Are there ongoing legal challenges? Did the patient die on full support or was the ventilator removed in ICU?

o Did you feel well supported during this conflict?

o What would you do differently/the same if a similar conflict came up during your next clinical shift?

- If NO: have you heard about this issue or discussed it with colleagues?

o What is your sense of the frequency of this type of conflict?

o What is your sense of the character of this type of conflict from the physician's perspective?

o What is your sense of the impact of this type of conflict on ICU care?

o What do you think are the reasons for this type of conflict?

o What do you think we can do about this type of conflict?

Q3 How do you think physicians could or should manage the challenge of family requests for continued organ support and/or refusal to withdraw of organ support 


\section{following a declaration of death using neurological criteria?}

- How have you managed it or heard about/seen it being managed by others?

- Requests for additional support?

- Moral distress?

- Resulting burnout? How much do you see this as an issue for yourself and your colleagues?

- Suggestions for the future?

Q4 Is there anything else you want to share with us about your experiences or thoughts surrounding family requests for continued organ support following a declaration of death using neurologic criteria?

\section{CONCLUSION}

- Thank you again for your time

- Please let me know if you'd like to be sent a copy of the results of this study

- Don't hesitate to reach out if you think of anything additional to add or if you have any questions for the study team

\section{References}

1. Shemie SD, Doig C, Dickens B, et al. Severe brain injury to neurological determination of death: Canadian forum recommendations. CMAJ 2006; 174: S1-12.

2. A definition of irreversible coma. Report of the ad hoc committee of the Harvard Medical School to examine the definition of brain death. JAMA 1968; 205: 337-40.

3. Kilcullen JK. "As good as dead" and is that good enough? Public attitudes toward brain death. J Crit Care 2014; 29: 872-4.

4. Siminoff LA, Burant C, Youngner SJ. Death and organ procurement: public beliefs and attitudes. Kennedy Inst Ethics J 2004; 14: 217-34.

5. Joffe AR, Anton NR, Duff JP, de Caen A. A survey of American neurologists about brain death: Understanding the conceptual basis and diagnostic tests for brain death. Ann Intensive Care 2012. https://doi.org/10.1186/2110-5820-2-4.

6. Joffe AR, Anton N, Mehta $V$. A survey to determine the understanding of the conceptual basis and diagnostic tests used for brain death by neurosurgeons in Canada. Neurosurgery 2007; 61: 1039-45; discussion 1046-7.

7. Joffe AR, Anton N. Brain death: understanding of the conceptual basis by pediatric intensivists in Canada. Arch Pediatr Adolesc Med 2006; 160: 747-52.

8. Lock $M$. Living cadavers and the calculation of death. Body Soc 2004; 10: 135-52. https://doi.org/10.1177/1357034X04042940.

9. Bernat $J L$. Refinements in the organism as a whole rationale for brain death. Linacre Q 2019; 86: 347-58.

10. Pope TM. Brain death forsaken: growing conflict and new legal challenges. J Leg Med 2017; 37: 265-324.

11. Fins JJ. Across the divide: religious objections to brain death. $\mathrm{J}$ Relig Health 1995; 34: 33-9.

12. Greer DM, Varelas PN, Haque S, Wijdicks EF. Variability of brain death determination guidelines in leading US neurologic institutions. Neurology 2008; 70: 284-9.

13. Shemie $S D$. Variability of brain death practices. Crit Care Med 2004; 32: 2564-5.
14. Sque $M$, Long T, Payne $S$, Allardyce $D$. Why relatives do not donate organs for transplants: 'Sacrifice' or 'gift of life'? J Adv Nurs 2008; 61: 134-44.

15. Manuel A, Solberg S, MacDonald S. Organ donation experiences of family members. Nephrol Nurs J 2010; 37: 229-36.

16. Long T, Sque M, Addington-Hall $J$. What does a diagnosis of brain death mean to family members approached about organ donation? A review of the literature. Prog Transplant 2008; 18: 118-25.

17. Long T, Sque M, Addington-Hall J. Conflict rationalisation: how family members cope with a diagnosis of brain stem death. Soc Sci Med 2008; 67: 253-61.

18. $d u$ Toit $J$, Miller $F$. The ethics of continued life-sustaining treatment for those diagnosed as brain-dead. Bioethics 2016; 30: 151-8.

19. Paris JJ, Cummings BM, Moore MP Jr. "Brain Death", "dead", and parental denial: the case of Jahi McMath. Cambridge Q Healthc Ethics 2014; 23: 371-82.

20. Ontario Superior Court of Justice. McKitty v. Hayani, 2018 ONSC 4015. 2018. Available from URL: https://www.canlii.org/en/on/ onsc/doc/2018/2018onsc4015/2018onsc4015.html (accessed September 2020).

21. Court of Appeal for Ontario. McKitty v. Hayani, 2019 ONCA 805. Available from URL: https://www.canlii.org/en/on/onca/ doc/2019/2019onca805/2019onca805.html\#document (accessed September 2020).

22. Ontario Superior Court of Justice. Ouanounou v. Humber River Hospital et al., 2018 ONSC 6511. CanLII; 2018.

23. Lewis A. Reconciling the case of Jahi McMath. Neurocrit Care 2018; 29: 20-2.

24. Luce JM. The uncommon case of Jahi McMath. Chest 2015; 147: 1144-51.

25. Aviv R. What does it mean to die? The New Yorker 2018. Available from URL: https://www.newyorker.com/magazine/ 2018/02/05/what-does-it-mean-to-die (accessed September 2020). 
26. Smith $M L$, Flamm AL. Accommodating religious beliefs in the ICU: a narrative account of a disputed death. Narrat Inq Bioeth 2011; 1: 55-64.

27. Elpern EH, Covert B, Kleinpell R. Moral distress of staff nurses in a medical intensive care unit. Am J Crit Care 2005; 14: 523-30.

28. Lewis A, Adams N, Varelas P, Greer D, Caplan A. Organ support after death by neurologic criteria: results of a survey of US neurologists. Neurology 2016; 87: 827-34.

29. Lewis A, Adams N, Chopra A, Kirschen MP. Organ support after death by neurologic criteria in pediatric patients. Crit Care Med 2017; 45: e916-24.

30. Consent and Capacity Board. In the matter of the Health Care Consent Act, 1996 R.S.O 1990, chapter M.7 as amended and in the matter of EI a patient at Trillium Health Partners Mississauga Hospital; 2016. Available from URL: http://www. thaddeuspope.com/images/EI_Ont_CCB_2016_.pdf (accessed September 2020).

31. Burns KE, Duffett $M$, Kho ME, et al. A guide for the design and conduct of self-administered surveys of clinicians. Can Med Assoc J 2008; 179: 245-52.

32. Silverman D. Doing Qualitative Research, 4th ed. Metzier K (Ed.). Los Angeles: Sage Publications; 2013: 199-209.

33. Hewitt-Taylor $J$. Use of constant comparative analysis in qualitative research. Nurs Stand 2001; 15: 39-42.

34. Guest G, MacQueen K, Namey EE. Applied Thematic Analysis. Thousand Oaks: SAGE Publications; 2014.
35. Cook DJ, Giancomini M, Johnson N, Willms D. Life support in the intensive care unit: a qualitative investigation of technological purposes. CMAJ 1999; 161: 1109-13.

36. Thurmond VA. The point of triangulation. J Nurs Scholarsh 2001; 33: 253-8.

37. Shemie SD, MacDonald S; Canadian Blood Services; Canadian Critical Care Society Expert Consultation Group. Improving the process of deceased organ and tissue donation: a role for donation physicians as specialists. CMAJ 2014; 18: 95-6.

38. Canadian Medical Association. Critical Care Medicine Profile; 2018. Available from URL: https://www.cma.ca/sites/default/ files/2019-01/critical-care-e.pdf (accessed September 2020).

39. Province of Manitoba. The Vital Statistics Act, Section 2. Available from URL: https://web2.gov.mb.ca/laws/statutes/ ccsm/v060e.php (accessed September 2020).

40. National Conference of Commissioners on Uniform State Laws. Uniform Determination of Death Act. United States of America; 1980. Available from URL: http://hods.org/English/h-issues/ documents/udda80.pdf (accessed September 2020).

41. Russell JA, Epstein LG, Greer DM, Kirschen M, Rubin MA, Lewis $A$. Brain death, the determination of brain death, and member guidance for brain death accommodation requests: AAN position statement. Neurology 2019; 92: 228-32.

Publisher's Note Springer Nature remains neutral with regard to jurisdictional claims in published maps and institutional affiliations. 